\title{
HIV and the Bone
}

\author{
Fabio Vescini
}

(C) Springer Science+Business Media, LLC 2012

At the end of 1999 my friend Marco Borderi came to me with a "hot" question: "I'm afraid that my HIV-positive patients can develop osteoporosis: how can we manage it?" I had been working on metabolic bone diseases since 1995, and I supposed I could treat his patients like all the others. We began to screen all HIV-positive subjects with dual X-ray absorptiometry (DXA), and we had the first surprise: A very high number of them had low bone mass, despite their relative young age. Moreover, males seemed to have a worse BMD than females. Some literature data were available involving mesenchymal stem cell infection, protease inhibitors, mild lactic acidosis and alterations in vitamin $\mathrm{D}$ metabolism and in bone turnover as possible etiological mechanisms of HIV-related metabolic bone disease. Finally, by those times none of us knew how to treat these patients.

As survival of HIV-positive individuals was rapidly increasing, we were forced to go deeper in the comprehension of HIV-related osteoporosis, and we wrote our first paper reporting prevalence of osteopenia and osteoporosis. Soon after, we joined some other Italian groups facing this problem, and we began to collaborate with Dr. Guaraldi, a well-known opinion leader in the field of HIV infection, who rapidly became a very good friend of mine. With him we conducted a pilot multicenter randomized study testing alendronate efficacy in reducing bone turnover of HIVpositive patients. Dr. Gibellini joined us later bringing his basic knowledge for the study of cellular cross talking.

F. Vescini $(\bowtie)$

Endocrinology and Metabolism Unit, University-Hospital

S. Maria della Misericordia, P.le S. Maria della Misericordia, 15,

33100 Udine, Italy

e-mail: fvescini@alice.it
Meanwhile, all over the world, literature was very rapidly growing, and in 2005, I received a surprising e-mail from Dr. Brown. In those days Todd was writing his fundamental meta-analysis on HIV-related osteoporosis, and he asked me for some of my unpublished data in order to include our paper in his work.

Since then, a very long distance has been covered, but we still have a long way to go.

This issue of Clinical Reviews in Bone and Mineral Metabolism aims to provide its readers a focus on different important aspects of HIV-related bone disease. To achieve this goal, we have called all the aforementioned friends together with Dr. Mallon, Dr. Ross and Dr. McComsey that are world-renowned researchers in this particular field.

Drs. Gibellini, Borderi, Vanino, Clò, Morini, Calza, Re and Viale will summarize the molecular bases of osteoporosis in HIV, highlighting the role of the virus and of antiretroviral therapy. Drs. Harris and Brown will review the prevalence of osteopenia, osteoporosis and fractures, while Drs. Guaraldi, Santoro and Domingues da Silva will focus on the aging skeleton. Drs. Cotter and Mallon are going deeper inside the emerging field of the cross talk between bone and fat in HIV-infected patients. Finally, Drs. Ross and McComsey will review the role of vitamin D deficiency in the pathogenesis of osteoporosis and in the modulation of the immune system in HIV-related bone disease.

On behalf of Dr. Angelo Licata, the Editor-in-Chief of CRBMM, and the authors of the reviews, I hope you will enjoy the articles complied within this special issue. I am also confident that they will provide useful information in the wide field of HIV-related osteoporosis and possibly will stimulate interest and research in the years ahead. 